\title{
Influence of terrain on metabolic and temporal gait characteristics of unilateral transtibial amputees
}

\author{
Jean Paysant, MD; ${ }^{1-2^{*}}$ Christian Beyaert, MD, PhD; ${ }^{1-2}$ Ange-Michel Datié, MD; ${ }^{1-3}$ Noël Martinet, $\mathrm{MD}, \mathrm{PhD}^{1}$ \\ Jean-Marie André, $\mathrm{MD}, \mathbf{P h D}^{1-2}$ \\ ${ }^{1}$ Institut Régional de Réadaptation de Nancy, Nancy, France; ${ }^{2}$ Faculté de Médecine, Université de Nancy, Nancy, \\ France; ${ }^{3}$ Centre Hospitalier Universitaire de Yopougon, Abidjan, Côte d'Ivoire
}

\begin{abstract}
The difficulties confronted by amputees during overground walking are rarely investigated. In this study, we evaluated, in real-world situations, the influence of ground surface on walking in young, active amputees by measuring temporal and spatial gait parameters (free walking speed [FWS], step length [SL], step rate), energy expenditure (EE) (e.g., oxygen uptake, oxygen cost $\left[\mathrm{O}_{2} \mathrm{C}\right]$ ), and Rating of Perceived Exertion (RPE). Ten active transtibial amputees and ten nondisabled control subjects walked at self-selected speeds on three types of ground surface (asphalt, mown lawn, and high grass). No significant differences were observed between the two groups on asphalt and mown lawn. Differences between nondisabled subjects and amputees occurred for FWS $(p=0.03)$ and $\mathrm{O}_{2} \mathrm{C}(p=0.04)$ on asphalt and mown lawn and for all variables in high grass. When amputees (even though very active) were exposed to a particularly difficult environment, their FWS decreased ( $p=$ $0.008)$ and their EE and RPE increased $(p=0.005)$ compared with nondisabled subjects. In high grass, both groups reduced their self-selected speeds $(-15 \%$ for control subjects and $-16 \%$ for amputees). Control subjects reduced their velocity by reducing both SL $(-8.7 \%)$ and cadence $(-7.1 \%)$, whereas amputees reduced their velocity by reducing SL (-17\%) only.
\end{abstract}

Key words: energy expenditure, ground surface, lower-limb amputee, metabolic characteristics, oxygen cost, oxygen rate, spatial gait parameters, temporal gait parameters, walking, walking speed.

\section{INTRODUCTION}

Human locomotion involves smooth advancement of the body with the least mechanical and physiological energy expenditure (EE) [1]. Oxygen cost $\left(\mathrm{O}_{2} \mathrm{C}\right)$ increases at both slow and fast walking speeds and is lowest at moderate speed for both nondisabled and disabled persons. However, studies on lower-limb amputees demonstrated that their oxygen uptake $\left(\dot{\mathrm{VO}}_{2}\right)$ was approximately the same as that of control subjects at customary walking speed, even though the amputees' customary walking speed was slower [2]. This increased energy cost (per meter) is a result of slower walking speed or higher rate of $\mathrm{V}_{2}$ (per minute), depending on the level of amputation and physical fitness [2-5].

In most studies, younger amputees (usually from traumatic injury) are not distinguished from older amputees (usually from vascular disease). In our clinical practice, young, active amputees experience little difficulty

Abbreviations: $\mathrm{EE}=$ energy expenditure, $\mathrm{FWS}$ = free walking speed, $\mathrm{O}_{2} \mathrm{C}=$ oxygen cost, RPE $=$ Rating of Perceived Exertion, $\mathrm{SL}=$ step length, $\mathrm{SR}=$ step rate, $\dot{\mathrm{V}} \mathrm{O}_{2}=$ oxygen uptake, $\mathrm{WR}=$ walk ratio.

*Address all correspondence to Jean Paysant, MD; Institut Régional de Réadaptation de Nancy, 34 Rue Lionnois, Nancy, France 54042; 33-3-83-39-34-34; fax: 33-3-83-39-3459. Email: jean.paysant@irr.u-nancy.fr

DOI: 10.1682/JRRD.2005.02.0043 
with their activities of daily living, but terrain-related conditions (e.g., uneven ground, decline, poor visibility) may cause some problems.

Researchers have conducted most gait studies in the laboratory at comfortable or defined speeds and measured the relationships between EE and incremental changes in walking speed, step rate (SR), or step length (SL) [6-7]. The type of walking surface and footwear has little effect on EE, unless the surface in the laboratory is extremely rough [8-9].

Generally, the researcher's goal is to investigate biomechanical parameters (center-of-mass motion, energy transfer mechanism) [10-11] and energy-related parameters that could be used to design and improve prosthetic equipment [12-13]. Studies conducted under real-world conditions [14] or on simulated terrain [15-16] are scarce compared with experiments on treadmills. Overground walking is a part of the quality of life of amputees, particularly active amputees who want to function well on a variety of terrains for their professional or recreational activities [17]. To our knowledge, no studies exist on the influence of terrain on $\mathrm{EE}$ or the strategies prosthesis-wearing amputees (or nondisabled subjects) use to adapt spatial and temporal gait parameters to terrain-related factors.

The fact that nondisabled subjects select structures and strategies that reduce EE for locomotion has been reported in older publications [8]. The center-of-mass vertical motion is the most frequently cited hypothesis [18-19]. Nondisabled subjects spontaneously walk at a speed that minimizes energy cost per unit distance [20-21] by adopting an optimal relationship between SL and SR [22-23]. Subjects who are unable to attain the preferred cadence are forced to ambulate in the higher energy-cost range [24]. Such observations are in agreement with data produced by simple mathematical models of optimal bipedal gait [25-26]. This cost-effective strategy has been demonstrated for nondisabled subjects who were walking [27], running [28], climbing stairs [29], and walking in sand [15].

Apparently, energy-sparing strategies are also adopted by hemiplegics [30] and amputees [31-32]. Like nondisabled subjects, hemiplegics and amputees also adopt strategies to achieve optimal mechanical and energetic adaptation to the environment. Knowledge of how these strategies operate in amputees in comparison with other disabled or nondisabled subjects could help us better understand the plasticity of what has been termed "the subtle mechanism of walking” [33].
We conducted this study to investigate, in real-world situations, the influence of ground surface on walking in prosthesis-wearing transtibial amputees compared with nondisabled subjects by measuring temporal and spatial gait parameters, EE, and Rating of Perceived Exertion (RPE). Specific research questions included:

- How much energy does a transtibial amputee expend in real-world situations on asphalt, mown lawn, and high grass?

- What SR and SL are adopted?

- Do young, active amputees adopt different strategies than nondisabled subjects with equivalent physical status?

\section{METHODS}

This study was conducted between 2001 and 2003 in two groups of subjects: transtibial amputees and nondisabled subjects. For the amputee group, inclusion criteria were (1) lower-limb unilateral amputation below the knee with section of the tibia, (2) amputation performed after trauma, (3) no other disease or disability, (4) no other history of surgery, (5) daily use of a well-fitted prosthesis for $\geq 1$ yr, (6) ability to walk without a limp and without an assistive device, and (7) resumed physical, occupational, and recreational activities. Characteristic features of the amputee group are presented in Table 1.

Each amputee was matched with a nondisabled control for sex, age, body weight, length of lower limbs, and level of physical activity [34]. Characteristics of the two groups are presented in Table 2. Eating, smoking, and caffeine intake were proscribed for $4 \mathrm{~h}$ before measurements were taken. All subjects volunteered to participate in the study and provided informed consent. The protocol received the approval of the District Human Ethics Committee at the Université de Nancy.

The amputee group was a young population (mean age $39.2 \mathrm{yr}$ ). Leg injury leading to amputation was the only traumatic event in 8 of the 10 subjects; traffic accidents predominated. Amputation occurred a mean of $17.4 \mathrm{yr}$ before the study. This population of very active subjects wore high-performance well-fitted prostheses with silicon liners and suspension sleeves or distal attachments. All the prostheses had an energy-storing foot and two of them had a complementary shock absorber. 
Table 1.

Selected characteristics of residual limb and prosthetic devices of amputees $(N=10)$.

\begin{tabular}{|c|c|c|c|c|c|c|c|c|}
\hline Subject & Sex & $\begin{array}{l}\text { Age } \\
\text { (yr) }\end{array}$ & $\begin{array}{l}\text { Activity } \\
\text { Level* }^{*}\end{array}$ & $\begin{array}{c}\text { Cause of Amputation } \\
\text { (Accident) }\end{array}$ & $\begin{array}{c}\text { Yr Since } \\
\text { Amputation }\end{array}$ & $\begin{array}{l}\text { Residual Limb } \\
\text { Length (cm) }\end{array}$ & $\begin{array}{c}\text { Prosthetic Socket/ } \\
\text { Suspension }\end{array}$ & $\begin{array}{c}\text { Foot-Ankle } \\
\text { Unit }\end{array}$ \\
\hline 1 & $\mathrm{M}$ & 51 & $\mathrm{~A}$ & Hunting & 32 & 20 & TSB/SL, S & ESF \\
\hline 2 & M & 33 & $\mathrm{R}$ & Automobile & 13 & 13 & TSB/SL, P & ESF \\
\hline 3 & $\mathrm{M}$ & 41 & A & Motorcycle & 13 & 17 & TSB/SL, P & ESF \\
\hline 4 & $\mathrm{M}$ & 45 & $\mathrm{R}$ & Occupational (crush) & 33 & 30 & TSB/SL, P & ESF \\
\hline 5 & $\mathrm{M}$ & 65 & $\mathrm{R}$ & Recreational & 38 & 15 & TSB/SL, S & ESF \\
\hline 8 & M & 28 & $\mathrm{C}$ & Occupational automobile & 10 & 24 & TSB/SL, P & ESF, SA \\
\hline 9 & M & 21 & A & Occupational (fracture) & 2 & 20 & TSB/SL, S & ESF \\
\hline 10 & M & 24 & $\mathrm{C}$ & Motorcycle & 3 & 25 & TSB/SL, P & ESF, SA \\
\hline
\end{tabular}

*Source: Dejour H. Results of the treatment of anterior laxity of the knee [In French]. Rev Chir Orthop Reparatrice Appar Mot. 1983;69(4):253-302 [PMID: 6226067]. $\mathrm{C}=$ competitive sports, $\mathrm{R}=$ recreational sports, $\mathrm{A}=$ active, $\mathrm{S}=$ sedentary, $\mathrm{TSB}=$ total surface bearing, $\mathrm{SL}=$ silicon liner, $\mathrm{P}=$ pin attachment, $\mathrm{S}=$ suspension sleeve, $\mathrm{ESF}=$ energy storing feet, $\mathrm{SA}=$ shock absorber.

Table 2.

Mean physical characteristics of two study groups (nondisabled, amputee; $N=20$ ).

\begin{tabular}{lccc}
\multicolumn{1}{c}{ Characteristic } & Amputee & Nondisabled & $\boldsymbol{p}^{-V a l u{ }^{*}}$ \\
\hline Age $(\mathrm{yr})$ & 39.2 & 39.7 & 0.13 \\
Height $(\mathrm{cm})$ & 178.1 & 175.6 & 0.10 \\
Weight $(\mathrm{kg})$ & 79.3 & 76.7 & 0.18 \\
Leg Length $(\mathrm{cm})$ & 95.9 & 92.3 & 0.09 \\
Baseline $\dot{\mathrm{VO}}_{2}\left(\mathrm{~mL} \mathrm{O}_{2} / \mathrm{kg} / \mathrm{min}\right)$ & 4.29 & 4.41 & 0.20 \\
\hline${ }^{*}{ }^{*}$ & & &
\end{tabular}

*Student's $t$-test.

$\dot{\mathrm{V}}_{2}=$ oxygen uptake.

All amputees had a high level of daily physical activity (generally occupational activity). Three amputees participated in recreational sports activities and two others in competitive sports.

All measurements were made outdoors on a flat surface. The track, although similar to a running track, had no half-turn (i.e., it was shaped like an oval). Each subject walked on three ground surfaces: asphalt, mown lawn (grass height $\sim 1$ in., 2-4 cm maximum), and untended uneven ground (grass height 5 in., $12-20 \mathrm{~cm}$ maximum). Measurements were made during warm $\left(18^{\circ}-24^{\circ} \mathrm{C}\right.$, mean $20.5^{\circ} \mathrm{C}$ ) sunny or cloudy, but not rainy, weather, on dry ground. Baseline measurements of $\mathrm{EE}$ and heart rate were made while subjects were in the sitting position under the same outdoor conditions after a 10 min rest.

The subjects were instructed to walk as naturally as possible. No instructions were given concerning speed, SR, or SL. The subjects walked on each of the 3 types of terrain for $10 \mathrm{~min}$. The order of the ground surfaces was randomized for each subject. Each recording lasted 10 $\min$. We retained the last 2 min of the recording for analysis so conditions would be stable (validated with $\mathrm{V}_{2}$ curve as generally recommended). After walking over each ground surface, the subject rested in the sitting position until $\dot{\mathrm{VO}}_{2}$ returned to the baseline level (5-11 min, mean 8 min $20 \mathrm{~s}$ ). The RPE was administered after subjects walked over each ground surface [35].

An experimenter observed and counted the number of steps taken over $100 \mathrm{~m}$ during the last $2 \mathrm{~min}$ of the recording. Verification was made a posteriori by analysis of a videotape recording. Average walking speed was expressed as the time (measured with a chronometer) required for a subject to walk the $100 \mathrm{~m}$. We calculated SR (steps/min), SL (meter/steps), and walk ratio (WR) [WR $=(\mathrm{SL} / \mathrm{SR})]$ from this $100 \mathrm{~m}$ data.

Indirect calorimetry was performed with the KB1-C ambulatory metabolic analysis open-circuit spirometrybased system (AeroSport, Inc, Ann Arbor, Michigan), which measures $\dot{\mathrm{VO}}_{2}$ and other physiological attributes (carbon dioxide production, minute ventilation, respiratory 
quotient) [36]. EE was derived from the measured $\dot{\mathrm{VO}}_{2}$. The KB1-C metabolic system contained electronic instrumentation, a battery, oxygen and carbon dioxide sensors, and telemetry connections to a microprocessor that permitted radio transmissions to a receiver and computer [37-38]. The subjects were required to wear a mouthpiece and a face mask. The KB1-C was programmed to measure $\dot{\mathrm{VO}}_{2}$ at 20-second intervals. We used a separate system (Polar Electro Oy, Kempele, Finland) to monitor heart rate. $\dot{\mathrm{VO}}_{2}$ was expressed in $\mathrm{mL} \mathrm{O}_{2} / \mathrm{kg} / \mathrm{min}$ and $\mathrm{O}_{2} \mathrm{C}$ in $\mathrm{mL} \mathrm{O}_{2} / \mathrm{kg} / \mathrm{m}$ [37].

We used independent student's $t$-tests to compare characteristic features of the amputee and control groups. Two-way analyses of variance were performed to assess the effect of ground surface (high grass vs mown lawn vs asphalt) and amputation (nondisabled vs amputee) on the variables: free walking speed (FWS), SL, SR, WR, $\dot{\mathrm{V}} \mathrm{O}_{2}$, $\mathrm{O}_{2} \mathrm{C}$, and RPE. The $\alpha$ for significance was set at 0.05 . When we obtained a significant $F$-statistic, we conducted a post hoc test using the Scheffé method to establish if amputees walk differently on grass than on asphalt and if they walk differently from nondisabled subjects on grass and on asphalt. We used the nonparametric MannWhitney test for RPE, a discontinuous nominal variable. Data were processed with StatView (Statistical Analysis Software, Cary, North Carolina).

\section{RESULTS}

The raw data of the two study groups (nondisabled and amputee) on each ground surface (asphalt, mown lawn, high grass) are presented in Table 3 . For the two groups, no significant differences were found between the asphalt and mown lawn conditions; Table 4 presents data on the asphalt and high-grass conditions.

The data in Table $\mathbf{4}$ also provide answers to the following questions about the young, active amputees in this study:

1. Do they walk differently on grass than on asphalt?

2. Do they walk differently from nondisabled subjects on asphalt?

3. Do they walk differently from nondisabled subjects on high grass?

We summarize here only the main results:

- Walking on high grass versus asphalt led to a decrease in FWS, an increase in $\dot{\mathrm{VO}}_{2}$, and an increase in RPE for amputees.

- FWS for the amputees decreased significantly from $89.3 \mathrm{~m} / \mathrm{min}$ on asphalt to $74.7 \mathrm{~m} / \mathrm{min}$ on the high grass $(p=0.009)$. $\mathrm{VO}_{2}$ reached $18.29 \mathrm{~mL} / \mathrm{kg} / \mathrm{min}$ on high grass ( $+7 \%$ asphalt).

- With the RPE scale, the amputees described their perceived exertion as "hard" on high grass versus "very light” on asphalt.

- Differences between amputees and nondisabled subjects on asphalt were found only for FWS and $\mathrm{O}_{2} \mathrm{C}$ (not for $\dot{\mathrm{V}} \mathrm{O}_{2}$ ), whereas major significant differences between amputees and nondisabled subjects were found for all the metabolic $\left(\dot{\mathrm{VO}}_{2}, \mathrm{O}_{2} \mathrm{C}\right.$, heart rate, RPE) and temporal gait characteristics (FWS, SL, SR) when walking on high grass.

For example, $\mathrm{O}_{2} \mathrm{C}$ on high grass was very high for the amputees $(0.245 \mathrm{~mL} / \mathrm{kg} / \mathrm{m})$ compared with the nondisabled subjects $(0.182 \mathrm{~mL} / \mathrm{kg} / \mathrm{m} ; p=0.006)$. Walking on the high grass was perceived as "hard" by the amputees and as "fairly light" by the nondisabled subjects ( $p=0.006)$.

Table 3.

Mean \pm standard deviation free walking speed (FWS), heart rate (HR), oxygen uptake $\left(\dot{\mathrm{V}}_{2}\right)$, oxygen cost $\left(\mathrm{O}_{2} \mathrm{C}\right)$, Rating of Perceived Exertion (RPE), step length (SL), step rate (SR), and walk ratio (WR) by type of terrain for two study groups (nondisabled, amputee; $N=20$ ).

\begin{tabular}{|c|c|c|c|c|c|c|c|c|}
\hline Terrain & $\begin{array}{c}\text { FWS } \\
(\mathrm{m} / \mathbf{m i n})\end{array}$ & $\begin{array}{c}\text { HR } \\
\text { (bpm) }\end{array}$ & $\begin{array}{c}\dot{\mathrm{V} O_{2}} \\
\left(\mathrm{~mL} \mathrm{O}_{2} / \mathrm{kg} / \mathrm{min}\right)\end{array}$ & $\begin{array}{c}\mathrm{O}_{2} \mathrm{C} \\
\left(\mathrm{mL} \mathrm{O} \mathrm{O}_{2} / \mathrm{kg} / \mathrm{min}\right)\end{array}$ & RPE & $\begin{array}{l}\text { SL } \\
(\mathrm{m})\end{array}$ & $\begin{array}{c}\text { SR } \\
\text { (step/min) }\end{array}$ & $\begin{array}{c}\text { WR } \\
\text { (m/step/min) }\end{array}$ \\
\hline \multicolumn{9}{|l|}{ Asphalt } \\
\hline Nondisabled & $91.4 \pm 6.7$ & $99.2 \pm 10.2$ & $13.43 \pm 0.21$ & $0.147 \pm 0.020$ & $9.1 \pm 0.7$ & $0.816 \pm 0.09$ & $112 \pm 4.1$ & $7.28 \times 10^{-3}$ \\
\hline Amputee & $89.3 \pm 9.2$ & $101.0 \pm 15.3$ & $14.55 \pm 0.19$ & $0.163 \pm 0.015$ & $8.7 \pm 0.5$ & $0.826 \pm 0.12$ & $108 \pm 7.3$ & $7.64 \times 10^{-3}$ \\
\hline \multicolumn{9}{|l|}{ Mown Lawn } \\
\hline Nondisabled & $90.1 \pm 9.4$ & $103.0 \pm 12.1$ & $14.05 \pm 0.15$ & $0.156 \pm 0.022$ & $9.6 \pm 1.1$ & $0.811 \pm 0.07$ & $111 \pm 6.2$ & $7.30 \times 10^{-3}$ \\
\hline \multicolumn{9}{|l|}{ High Grass } \\
\hline Nondisabled & $77.5 \pm 9.8$ & $107.0 \pm 13.5$ & $15.63 \pm 0.14$ & $0.182 \pm 0.023$ & $12.3 \pm 1.7$ & $0.745 \pm 0.11$ & $104 \pm 9.2$ & $7.16 \times 10^{-3}$ \\
\hline Amputee & $74.7 \pm 6.9$ & $115.0 \pm 16.8$ & $18.29 \pm 0.20$ & $0.245 \pm 0.015$ & $16.9 \pm 0.9$ & $0.685 \pm 0.10$ & $109 \pm 11.4$ & $6.28 \times 10^{-3}$ \\
\hline
\end{tabular}


Table 4.

Mean \pm standard deviation free walking speed (FWS), heart rate (HR), oxygen uptake $\left(\dot{\mathrm{V}}_{2}\right)$, oxygen cost $\left(\mathrm{O}_{2} \mathrm{C}\right)$, Rating of Perceived Exertion (RPE), step length (SL), step rate (SR), and walk ratio (WR) by type of terrain (asphalt, high grass) for two study groups (nondisabled, amputee; $N=20$ ).

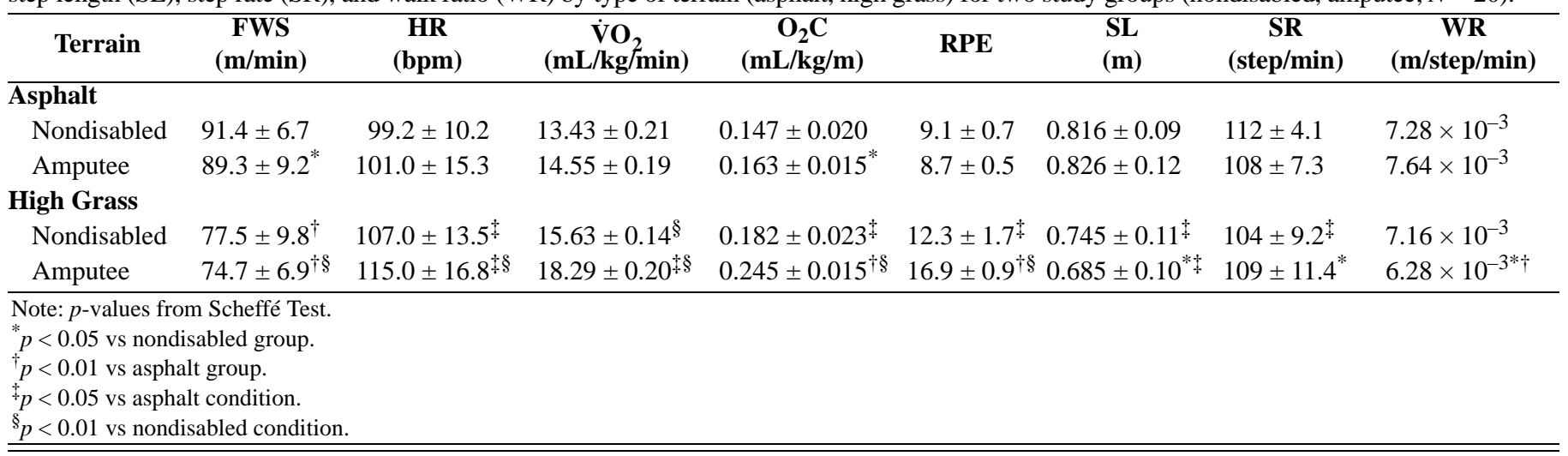

In high grass, the nondisabled subjects reduced their velocity by reducing both SL $(-9 \%)$ and cadence $(-7 \%)$, whereas the amputees reduced their velocity by reducing SL (-17\%) only.

\section{DISCUSSION}

This study reported the effect of different types of terrain on the metabolic and temporal gait characteristics of young active, male transtibial amputees compared with matched control subjects. This study is original because the measurements were conducted in real-world conditions.

EEs recorded in the control group at rest and when walking were in line with data reported for active male subjects $[20,27,39]$. The $\dot{\mathrm{VO}}_{2}$ rate for control subjects when walking was slightly higher than [40] or similar to [1] that generally reported because our physically fit population adopted a more rapid spontaneous pace. $\mathrm{O}_{2} \mathrm{C}$ [40] was similar to [1] or slightly lower than in earlier reports [41], since our control subjects walked much faster than other populations reported earlier [41-44]. The values for metabolic and gait temporal characteristics of our amputees were similar to those reported for healthy young subjects while walking fast [2,27,45-46].

This similarity found between nondisabled subjects and our amputee group is interesting and probably related to the fact that the study population was among the most fit and active subset of individuals with lower-limb loss. Level of physical fitness is the main factor that improves walking efficiency and associated energy cost $[1,40]$. However some differences in spontaneous speed (aver- age speed was measured in this experiment) may be possible between nondisabled and amputee subjects.

When walking on asphalt at a self-selected speed, nondisabled and amputee subjects exhibited no differences, except FWS, $p=0.03$ and $\mathrm{O}_{2} \mathrm{C}, p=0.04$. This surprising result can, at least partly, be explained by the selected population of amputees with characteristics (height, body weight, age, level of physical activity, occupational activity) similar to the matched control subjects; the measures might simply not be sensitive enough for us to discern differences between the two populations and the sample size might not be large enough. One should be careful in generalizing these results because our study was specifically directed at young, active transtibial posttraumatic amputees. The $\mathrm{O}_{2} \mathrm{C}$ difference is probably related to the slower speed because $\mathrm{VO}_{2}$ in this study was the same for both nondisabled and amputated subjects.

Nondisabled and amputee subjects did not differ when walking on mown lawn versus asphalt; this result is not surprising because the grass was short $(<5 \mathrm{~cm})$ and the surface could be seen easily.

When the subjects walked on high grass, the increased $\mathrm{EE}$ became evident. In the control subjects, $\mathrm{O}_{2} \mathrm{C}$ increased despite the minimal observed change in FWS. In the amputees, EE increased because of increased $\dot{\mathrm{V}}_{2}$ and decreased speed. Possible explanations for the increased EE when subjects walked in high grass are an increase in resistance and friction of the long grass on the feet, an increase in lifting of the lower limb, and apprehension related to not being able to see the surface under the uneven grass. These factors may also contribute to the slower gait for nondisabled subjects and, more obviously, for amputees. A slower gait is probably 
more reassuring in the presence of an uneven surface, particularly for amputees who need to control a prosthetic device.

The results concerning the temporospatial characteristics (SL, SR, and WR) are interesting. We know that the same walking speed can be achieved with different combinations of SL and SR, but when asked to walk at a comfortable self-selected speed, a subject adopts a specific SL and SR that determine the WR (SL/SR) [47-48]. The WR is considered a general law of human locomotion [22,49].

In our study, the WR remained constant in the nondisabled subjects for all terrains (simultaneous adaptation of SL and SR). The nondisabled subjects appeared to be able to adapt these two parameters without changing the level of exertion or increasing EE. Our physically fit amputees displayed the same type of adaptation under normal walking conditions. However, when the terrain became more difficult, their SR remained unchanged but the stride length became shorter. This raised the WR and concurrently EE. The hypothesis of a lack of optimization in SR has been formulated. A study by Danion et al. [50] on the temporospatial variability of step parameters in nondisabled subjects led to the hypothesis that the spontaneously selected SR is the optimal SR [23,51]. A parallel hypothesis can be formulated concerning the temporospatial variability of gait parameters and the relationship between optimal EE and a constant WR. In nondisabled subjects, gait variability is lowest at a SR of $1 \mathrm{~Hz}$ (a U-shaped curve). The effect of SL on gait variability is different: longer strides correlate with less variability (a straight line relationship) [50].

Is the SR a preprogrammed or regulated parameter related to energy efficiency or is the SR only a consequence of center-of-mass motion and energy transfer between limb segments [18,52-55]? Further studies are needed to explore this question. A cause-and-effect statement that the increased metabolic cost is related to the change in temporal characteristics cannot be affirmed; the metabolic demands of the activity may cause the subjects to modify their temporal gait characteristics to minimize the metabolic consequences.

\section{CONCLUSION}

Changes in terrain (asphalt, mown lawn, high grass) modify the metabolic and temporal gait characteristics of nondisabled and transtibial amputee subjects. In both subject groups, self-selected velocity decreased and EE increased.

Differences between 10 young, active male transtibial posttraumatic amputees who wore high-performance prostheses and 10 nondisabled subjects occurred only for FWS $(p=0.03)$ and $\mathrm{O}_{2} \mathrm{C}(p=0.04)$ on asphalt and mown lawn, whereas differences emerged for all the metabolic and temporal gait characteristics in high grass. The amputee's locomotion disability becomes a significant factor when exposed to a particularly difficult environment, such as uneven ground: the amputees walked slightly slower with higher EE and RPE. On this uneven terrain, the control subjects reduced their velocity by reducing both SL and cadence, whereas amputees reduced their velocity by reducing SL only.

\section{ACKNOWLEDGMENTS}

This material was unfunded at the time of manuscript preparation.

The authors have declared that no competing interests exist.

\section{REFERENCES}

1. Waters RL, Mulroy S. The energy expenditure of normal and pathologic gait. Gait Posture. 1999;9(3):207-31.

[PMID: 10575082]

2. Huang CT, Jackson JR, Moore NB, Fine PR, Kuhlemeier KV, Traugh GH, Saunders PT. Amputation: Energy cost of ambulation. Arch Phys Med Rehabil. 1979;60(1):18-24. [PMID: 420566]

3. Gonzalez EG, Corcoran PJ, Reyes RL. Energy expenditure in below-knee amputees: Correlation with stump length. Arch Phys Med Rehabil. 1974;55(3):111-19. [PMID: 4817680]

4. James U, Nordgren B. Physical work capacity measured by bicycle ergometry (one leg) and prosthetic treadmill walking in healthy active unilateral above-knee amputees. Scand J Rehabil Med. 1973;5(2):81-87. [PMID: 4695244]

5. Pinzur MS, Gold J, Schwartz D, Gross N. Energy demands for walking in dysvascular amputees as related to the level of amputation. Orthopedics. 1992;15(9):1033-36; discussion 1036-37. [PMID: 1437862]

6. Rietman JS, Postema K, Geertzen JH. Gait analysis in prosthetics: Opinions, ideas and conclusions. Prosthet Orthot Int. 2002;26(1):50-57. [PMID: 12043926] 
7. Prince F, Winter DA, Sjonnensen G, Powell C, Wheeldon RK. Mechanical efficiency during gait of adults with transtibial amputation: A pilot study comparing the SACH, Seattle, and Golden-Ankle prosthetic feet. J Rehabil Res Dev. 1998;35(2):177-85. [PMID: 9651889]

8. Passmore R, Durnin JV. Human energy expenditure. Physiol Rev. 1955;35(4):801-40. [PMID: 13266530]

9. Ralston HJ. Comparison of energy expenditure during treadmill walking and floor walking. J Appl Physiol. 1960; 15:1156. [PMID: 13739280]

10. Grabowski A, Farley CT, Kram R. Independent metabolic costs of supporting body weight and accelerating body mass during walking. J Appl Physiol. 2005;98(2):579-83. [PMID: 15649878$]$

11. Orendurff MS, Segal AD, Klute GK, Berge JS, Rohr ES, Kadel NJ. The effect of walking speed on center of mass displacement. J Rehabil Res Dev. 2004;41(6):829-34. [PMID: 1568471$]$

12. Casillas JM, Dulieu V, Cohen M, Marcer I, Didier JP. Bioenergetic comparison of a new energy-storing foot and SACH foot in traumatic below-knee vascular amputations. Arch Phys Med Rehabil. 1995;76(1):39-44. [PMID: 7811172]

13. Torburn L, Perry J, Ayyappa E, Shanfield SL. Below-knee amputee gait with dynamic elastic response prosthetic feet: A pilot study. J Rehabil Res Dev. 1990;27(4):369-84. [PMID: 2089148]

14. White RG, Yousef MK. Energy expenditure in reindeer walking on roads and tundra. Can J Zool. 1978;56:215-23.

15. Lejeune TM, Willems PA, Heglund NC. Mechanics and energetics of human locomotion on sand. J Exp Biol. 1998; 201(Pt 13):2071-80. [PMID: 9622579]

16. Zamparo P, Perini R, Orizio C, Sacher M, Ferretti G. The energy cost of walking or running on sand. Eur J Appl Physiol Occup Physiol. 1992;65(2):183-87. [PMID: 1327762]

17. Legro MW, Reiber G, Del Aguila M, Ajax MJ, Boone DA, Larsen JA, Smith DG, Sangeorzan B. Issues of importance reported by persons with lower limb amputations and prostheses. J Rehabil Res Dev. 1999;36(3):155-63.

[PMID: 10659798]

18. Minetti AE, Capelli C, Zamparo P, Di Prampero PE, Saibene F. Effects of stride frequency on mechanical power and energy expenditure of walking. Med Sci Sports Exerc. 1995;27(8):1194-1202. [PMID: 7476065]

19. Neptune RR, Zajac FE, Kautz SA. Muscle mechanical work requirements during normal walking: The energetic cost of raising the body's center-of-mass is significant. J Biomech. 2004;37(6):817-25. [PMID: 15111069]

20. Blessey RL, Hislop HJ, Waters RL, Antonelli D. Metabolic energy cost of unrestrained walking. Phys Ther. 1976; 56(9):1019-24. [PMID: 959328]
21. Molen NH, Rozendal RH, Boon W. Graphic representation of the relationship between oxygen-consumption and characteristics of normal gait of the human male. Proc K Ned Akad Wet C. 1972;75(4):305-14. [PMID: 4263757]

22. Hay JG. Cycle rate, length, and speed of progression in human locomotion. J Appl Biomech. 2002;18(3):257-70.

23. Sekiya N, Nagasaki H, Ito H, Furuna T. Optimal walking in terms of variability in step length. J Orthop Sports Phys Ther. 1997;26(5):266-72. [PMID: 9353690]

24. Holt KG, Hamill J, Andres RO. Predicting the minimal energy costs of human walking. Med Sci Sports Exerc. 1991;23(4):491-98. [PMID: 1905381]

25. Anderson FC, Pandy MG. Dynamic optimization of human walking. J Biomech Eng. 2001;123(5):381-90.

[PMID: 11601721]

26. Minetti AE, Alexander RM. A theory of metabolic costs for bipedal gaits. J Theor Biol. 1997;186(4):467-76.

[PMID: 9278722]

27. Waters RL, Lunsford BR, Perry J, Byrd R. Energy-speed relationship of walking: Standard tables. J Orthop Res. 1988;6(2):215-22. [PMID: 3343627]

28. Ferris DP, Liang K, Farley CT. Runners adjust leg stiffness for their first step on a new running surface. J Biomech. 1999;32(8):787-94. [PMID: 10433420]

29. Shiomi T. Effects of different patterns of stairclimbing on physiological cost and motor efficiency. J Hum Ergol (Tokyo). 1994;23(2):111-20. [PMID: 7730596]

30. Corcoran PJ, Jebsen RH, Brengelmann GL, Simons BC. Effects of plastic and metal leg braces on speed and energy cost of hemiparetic ambulation. Arch Phys Med Rehabil. 1970;51(2):69-77. [PMID: 5437126]

31. Hoffman MD, Sheldahl LM, Buley KJ, Sandford PR. Physiological comparison of walking among bilateral above-knee amputee and able-bodied subjects, and a model to account for the differences in metabolic cost. Arch Phys Med Rehabil. 1997;78(4):385-92. [PMID: 9111458]

32. Ralston HJ. Energy-speed relation and optimal speed during level walking. Int Z Angew Physiol. 1958;17(4):277-83. [PMID: 13610523]

33. Pailhous J, Bonnard M. Steady-state fluctuations of human walking. Behav Brain Res. 1992;47(2):181-89.

[PMID: 1590948]

34. Dejour H. Results of the treatment of anterior laxity of the knee [In French]. Rev Chir Orthop Reparatrice Appar Mot. 1983;69(4):253-302. [PMID: 6226067]

35. Borg G. Perceived exertion as an indicator of somatic stress. Scand J Rehabil Med. 1970;2(2):92-98.

[PMID: 5523831]

36. Macfarlane DJ. Automated metabolic gas analysis systems: A review. Sports Med. 2001;31(12):841-61. [PMID: 11665912] 
37. King GA, McLaughlin JE, Howley ET, Bassett DR Jr, Ainsworth BE. Validation of Aerosport KB1-C portable metabolic system. Int J Sports Med. 1999;20(5):304-8. [PMID: 10452227]

38. Subudhi AW, Walker JA. Assessment of the Aerosport Ambulatory Metabolic Measurement System. J Human Mov Studies. 1999;37:205-16.

39. Waters RL, Hislop HJ, Perry J, Thomas L, Campbell J. Comparative cost of walking in young and old adults. J Orthop Res. 1983;1(1):73-76. [PMID: 6679578]

40. Torburn L, Powers CM, Guiterrez R, Perry J. Energy expenditure during ambulation in dysvascular and traumatic below-knee amputees: A comparison of five prosthetic feet. J Rehabil Res Dev. 1995;32(2):111-19. [PMID: 7562650]

41. Gailey RS, Wenger MA, Raya M, Kirk N, Erbs K, Spyropoulos P, Nash MS. Energy expenditure of transtibial amputees during ambulation at self-selected pace. Prosthet Orthot Int. 1994;18(2):84-91. [PMID: 7991365]

42. Fisher SV, Gullickson G Jr. Energy cost of ambulation in health and disability: A literature review. Arch Phys Med Rehabil. 1978;59(3):124-33. [PMID: 148252]

43. Ward KH, Meyers MC. Exercise performance of lowerextremity amputees. Sports Med. 1995;20(4):207-14. [PMID: 8584846]

44. Waters RL, Perry J, Antonelli D, Hislop H. Energy cost of walking of amputees: The influence of level of amputation. J Bone Joint Surg Am. 1976;58(1):42-46. [PMID: 1249111]

45. Lehmann JF, Price R, Boswell-Bessette S, Dralle A, Questad K. Comprehensive analysis of dynamic elastic response feet: Seattle Ankle/Lite Foot versus SACH foot. Arch Phys Med Rehabil. 1993;74(8):853-61. [PMID: 8347071]
46. Pearce ME, Cunningham DA, Donner AP, Rechnitzer PA, Fullerton GM, Howard JH. Energy cost of treadmill and floor walking at self-selected paces. Eur J Appl Physiol Occup Physiol. 1983;52(1):115-19. [PMID: 6686120]

47. Inman VT, Ralston HJ, Todd F. Human walking. Lewiston (KY): Edwin Mellen Press; 1989.

48. Winter DA. Kinematic and kinetic patterns in human gait: Variability and compensating effects. Hum Mov Sci. 1984; 3:51-76.

49. Zarrugh MY, Todd FN, Ralston HJ. Optimization of energy expenditure during level walking. Eur J Appl Physiol Occup Physiol. 1974;33(4):293-306. [PMID: 4442409]

50. Danion F, Varraine E, Bonnard M, Pailhous J. Stride variability in human gait: The effect of stride frequency and stride length. Gait Posture. 2003;18(1):69-77.

[PMID: 12855302]

51. Holt K, Jeng S, Ratcliffe R, Hamill J. Energetic cost and stability during human walking at the preferred stride frequency. J Mot Behav. 1995;27(2):164-78. [PMID: 12736125]

52. Doke J, Donelan JM, Kuo AD. Mechanics and energetics of swinging the human leg. J Exp Biol. 2005;208(Pt 3):439-45. [PMID: 15671332]

53. Kuo AD, Donelan JM, Ruina A. Energetic consequences of walking like an inverted pendulum; step-to-step transitions. Exerc Sport Sci Rev. 2005;33(2):88-97. [PMID: 15821430]

54. Robertson DG, Winter DA. Mechanical energy generation, absorption and transfer amongst segments during walking. J Biomech. 1980;13(10):845-54. [PMID: 7462258]

55. Siegel KL, Kepple TM, Stanhope SJ. Joint moment control of mechanical energy flow during normal gait. Gait Posture. 2004;19(1):69-75. [PMID: 14741305]

Submitted for publication February 11, 2005. Accepted in revised form September 19, 2005. 